\title{
Is there a Role for Autoimmunity in Immune Protection against Malaria?
}

\section{Cláudio Tadeu Daniel-Ribeiro}

Laboratório de Pesquisas em Malária, Instituto Oswaldo Cruz, Brazil and Service des Maladies Infectieuses et Tropicales, Centre Hospitalier Universitaire Saint Antoine, Université de Paris VI, France

Much remains to be known about the mechanisms involved in protective immunity against malaria and the way it is acquired. This is probably the reason why, in spite of so much progress, it has not yet been possible to develop an anti-malaria vaccine able to induce parasite specific antibodies $(A b)$ and/ or T-cells.

It has been considered in the early 80s that the induction of efficient protection against the blood stage forms of Plasmodium falciparum would not be possible without simultaneously eliciting an autoimmune (AI) response against erythrocytes, even at the price of inducing an AI pathology. Despite the description of the reciprocal relationship, i.e. the protective effect of malaria on the development of AI diseases - demonstrated since 1970 - no effort has been made to verify the possible involvement of the AI response in protection against malaria.

With this end in view - and in the light of the knowledge acquired in autoimmunity and the existence of the so called "natural" (not associated with pathology) autoantibodies - we propose to examine the hypothesis that the participation of the AI response (not necessarily restricted to autologous erythrocyte antigens) in the immune protection against malaria is possible or even necessary.

Key words: malaria - Plasmodium - autoimmunity - autoantibodies - immune protection - premunition vaccination

Immunology arose as an individualised discipline at the end of the XIX century with the works of Pasteur, establishing the basis of reproducibility and the rational basis for the expansion of vaccination: the artificial process of immunisation against infectious diseases. This strategy was based on the observation that several viral and bacterial diseases affect individuals only once: after primoinfection the individual was "exempt from the charge" of a second infection (etymology of the words "immune" and "immunity").

During the first half of the XX century, a significant number of bacterial and viral vaccines was produced by technologies that progressed only slowly. To take an example: the vaccine that permitted the eradication of smallpox at the end of the 70s was, in reality, achieved by inoculation, in

\footnotetext{
The author was recipient of a fellowship from the Conselho Nacional de Desenvolvimento Científico e Tecnológico (CNPq).

Present address: Laboratório de Pesquisas em Malária, Departamento de Imunologia, Instituto Oswaldo Cruz, Av. Brasil 4365, 21045-900 Rio de Janeiro, RJ, Brasil Fax: +55-21-280.1589. E-mail: ribeiro@ioc.fiocruz.br Received 8 October 1999

Accepted 28 December 1999
}

man, of the virus of the cowpox bovine disease (the vaccinia) that presents the property of crossprotection with human smallpox. Such procedure was not safe and was even capable of inducing secondary reactions, some of which being very severe.

This methodology has been progressively replaced by the use of killed, inactivated or attenuated live pathogens. Progresses in biochemistry, immunology and molecular biology during the last years allowed the use of vaccines composed of purified or recombinant proteins. The lesson resulting from this technological development, however, is that (with the exception of tetanous toxoid) we have only learnt to produce vaccines corresponding to diseases for which there is a "natural" - disease induced - immunity. We left to "later on" (and the "later on" never arrived!) the production of vaccines for diseases against which nature does not know (or knows very imperfectly) how to immunise. Among them one can easily include parasitic diseases - by definition, due to organisms very well adapted to their hosts. From an immunological point of view, this adaptation includes, among other parasite "escape-mechanisms" (intracellular parasitism, immunosuppression, polyclonal lymphocyte activation...) "molecular mimicry", expressed as a very marked phenomenon of antigen sharing between parasites and 
hosts. This "strategy" corresponds, in reality, to the selection of parasites best adapted to their environment. In this way, those having on their surface the largest number of antigens $(\mathrm{Ag})$ mimicking host $\mathrm{Ag}$ would have less risk of being recognised as "foreigners" and of being rejected and therefore more chances of living a long-lasting cohabitation with the organism from which they obtain food as "professional opportunists".

Our opinion is precisely that, in order to obtain efficient protection against plasmodial (or even other protozoan or parasite) infection, at least part of the immune response generated against the parasite must simultaneously recognise host-parasite shared Ag, thus constituting an AI response (an immunological response directed against components of its own organism i.e. "self" or autoantigens - AAg). As we shall see in the development of the paper, it is also possible that autoantibodies (AAb - antibodies directed against self) are not necessarily parasite reactive but are rather specific of parasite ligants on erythrocyte and/or of parasite derived material (phospolipids?) endowed with properties of mitogenicity or tumour necrosis factor (TNF) induction. The general idea has been considered in the past by Jayawardena et al. (1979) according to whom part of the malaria associated IgM response would be constituted by "protective $A A b$ " - and developed subsequently by Jarra (1983). According to the latter, the induction of protective immunity against intra-erythrocytic forms of Plasmodia would not be possible without the triggering of an immunological response to autologous red blood cell (RBC) components, which may simultaneously induce immunopathology. However, so far, no research effort has been made in order to verify this possibility.

In the present work we show that the relationship between autoimmunity and malaria is not an exceptional phenomenon. We discuss data showing that the immunological response against $\mathrm{AAg}$ is in fact induced in mammals during the process of acquisition of anti-toxic and/or anti-parasite natural-immunity. We draw attention to the evidence now available that autoreactivity can indeed exist without inducing any AI disease and that, even inversely, malaria (maybe precisely because of the autoimmunity it induces) protects against the development of AI diseases (diseases caused by an AI response). In the light of the knowledge acquired regarding the existence of so called "natural autoimmunity" (not associated with pathology), we propose that the development of autoimmunity be accepted (or even aimed at) in the design of immuno-prophylatic procedure so that the protection of humans against malaria can be effective. A set of experiments, that could help to test this hypothesis, is finally proposed in conclusion.

\section{AUTOIMMUNITY IN THE COURSE OF MALARIA INFECTION}

Little data indicate that some of the clinical manifestations of malaria can result from an AI process (Sorensen et al. 1984, Wozencraft et al. 1990). On the other hand, numerous biological signs of autoimmunisation are apparent in the course of acute disease or among individuals chronically exposed to infection. These signs relate to AAg such as double and single stranded DNA (Quakyi et al. 1979, Daniel-Ribeiro et al. 1984b, Zouali et al. 1986), erythrocyte (Facer et al. 1979, Facer 1980, Lefrançois et al. 1981, 1982), lymphocyte (De Souza \& Playfair 1983), phospholipid (Bate et al. 1992a, b, Facer \& Agiostratidou 1994, Bordmann et al. 1998), ribonucleoprotein (Greenwood et al. 1970a, Daniel-Ribeiro et al. 1983, 1991, Zouali et al. 1986), RNA (Kreier \& Dilley 1969), and smooth muscle (Quackyi et al. 1979, Daniel-Ribeiro et al. 1991) $\mathrm{Ag}$ and not to relate to organ-specific partially sequestered AAg such as thyroglobulin (DanielRibeiro et al. 1984a). This suggests that the formed $\mathrm{AAb}$ would result from specific activation of autoreactive B-lymphocytes and not from the activation of these cells within the framework of a generalised polyclonal B-cell activation (PBA) (Daniel-Ribeiro et al. 1984a, Daniel-Ribeiro 1988). We have proposed (Burger-Rolland et al. 1992) that the specificity of the process is the consequence of a "two signal" mechanism of cellular activation, depending both on the presence of immunogenic amounts of the corresponding AAg (signal 1) and on parasite mitogens (Freeman \& Parish 1978, Kataaha et al. 1984) able to replace the second signal usually delivered by $\mathrm{T}$ Cells that - in the case of AI responses - are under efficient and stringent control.

It seems also that the specificity of produced $\mathrm{AAb}$ differs according to the degree of anti-toxic or anti-parasite immunity. In this way, anti-nuclear $\mathrm{Ab}$ (ANA) are often observed in immune animals and among individuals chronically exposed to infection (Poels et al. 1980, Daniel-Ribeiro et al. 1983), while smooth muscle Ab (SMA) are detected in the course of the acute infection (Quackyi et al. 1979, Poels et al. 1980, Ben-Slama 1982, Daniel-Ribeiro et al. 1991). Since it has been clearly shown in man, at least as far as ANA and antiSMA are concerned, that the production of AAb during malaria does not depend on racial factors (Voller et al. 1972, Daniel-Ribeiro et al. 1991), these observations suggest the existence of a correlation between autoreactivity and immune-protection or degree of exposure to malaria.

In the same way, the existence and the pattern of AI response seem to be related to the clinical form of the disease and/or to the virulence of the Plasmo- 
dium infecting species or strain. De Souza and Playfair (1983) have shown that the anti-lymphocyte AAb induced by infection with $P$. berghei or $P$. yoelii-17XL (two lethal strains) are absent in mice infected with the non-lethal 17XNL-strain. Moreover, the injection of irradiated $P$. berghei that usually triggers the production of such AAb has not the same effect in mice previously infected with $P$. yoelii$17 \mathrm{XNL}$, thereby suggesting the existence of a suppressor mechanism induced by the non lethal infection. Although it does not affect responses against heterologous $\mathrm{Ag}$ such as RBC from sheep this mechanism seems to have a marked degree of crossreactivity with other AI responses. In fact, spleen cells from mice infected with the non-lethal strain, can suppress not only anti-lymphocyte responses but also those directed against autologous erythrocytes induced by the injection of cross-reacting rat $\mathrm{RBC}$ in normal mice (Playfair et al. 1985).

\section{DOES AUTOIMMUNITY PROTECT AGAINST MALARIA?}

Jaywardena et al. (1979) first proposed that part of the malaria associated IgM response could be constituted by "protective AAb" directed to RBC modified determinants or against crypto-Ag exposed at the erythrocyte membrane, as a consequence of the parasitisation. While admitting not knowing precisely how AAb could act at the level of $\mathrm{RBC}$ to limit parasite growth, these authors assumed that alterations of the erythrocyte membrane induced by AAb could contribute to the control of the primary infection.

This possibility has practically not been studied so far, but the hypothesis was taken-up again by Jarra (1983). According to him anti-erythrocyte autoreactivity could be an essential component of protective immunity against Plasmodium blood stages, even though it could also cause immunopathology.

The AI response against RBC in the course of malaria infection has indeed been demonstrated on several occasions in humans (Facer et al. 1979, Facer 1980, Lefrançois et al. 1981, 1982). Zouali et al. (1982) showed that Africans living in malaria hyper-endemic areas as well as Europeans presenting an acute episode of the disease, had high titres of $\mathrm{Ab}$ directed to T-erythrocyte crypto-Ag that are only exposed after enzymatic treatment of RBC. In the same way, it has been shown that experimental $P$. berghei infection is accompanied by an important B-cell response against bromelintreated mouse RBC (Rosenberg 1978).

Jarra (1983) also admitted that the intra-erythrocytic development of Plasmodium could induce cellular membrane alterations (expression of neo$\mathrm{Ag}$ and exposition of crypto-Ag) leading to the rup- ture of immune tolerance to AAg or modified AAg. This author used serological and immunocytochemical studies to show that sera from $P$. berghei infected or immune mice had $\mathrm{Ab}$ to iso- $\mathrm{Ag}$ determinants of the parasitised RBC. Ag specifically associated with parisitized erythrocyte was revealed - in absorption studies - to be closely associated with erythrocyte $\mathrm{Ag}$ at the surface membrane.

One alternative, and not conventional, manner of explaining anti-erythrocyte autoimmunity has been proposed by Sayles and Wasson (1992); according to these authors anti-RBC AAb could be anti-idiotype $\mathrm{Ab}$ reacting with anti-plasmodial $\mathrm{Ab}$ specific for parasite ligands of erythrocyte receptors.

However, the RBC specific AI response during malaria infection has always been proposed to explain the anaemia, that in spite of the intra-erythrocytic parasitism, is not related to the importance of the parasitaemia and can arise even in the absence of any circulating parasite. The originality of Jayawardena and collaborators and of Jarra has thus been to propose a protective role for these AAb. Literature effectively provides a certain number of arguments supporting this hypothesis and suggests that it should not be restricted to the antierythrocyte $\mathrm{AAb}$.

The extensive RBC modification and destruction, artificially generated by treatment of mice with phenylhydrazine is in fact followed by an increase in immunity against $P$. chabaudi infection. On the other hand, the induction of anti-erytrhrocytic $\mathrm{AAb}$ in mice by the injection of cross-reacting rat $\mathrm{RBC}$, failed to augment immunity against malaria (Jarra 1983).

A very interesting work (Hogh et al. 1994) concerned the immune response developed against band 3 neo-Ag of $P$. falciparum-infected erythrocyte. Ab against these Ag block the cytoadherence of infected RBC. At present it is not known whether reactivity to these $\mathrm{Ag}$ simply reflects the exposure to the malaria parasite or is correlated with protective immunity. However, children and adults living in an area of intense malaria transmission showed a much higher reactivity with the band 3 peptides than those from non-immune individuals. High reactivity to the loop 3 peptides was correlated with lower mean parasite density in children in the 5- to 9-year-old age group. Inversely, higher than average reactivities against loop 3 and 7 peptides were positively correlated with high hematocrit values, indicating that these $\mathrm{Ab}$ are not involved in haemolysis (through autoimmunity) and, on the contrary, suggesting that they can be involved in protection.

Besides anti-erythrocyte Ab, the AAb observed during the course of malaria are those that classi- 
cally accompany non-organ specific AI diseases, such as systemic lupus erythematosus (SLE). In addition to ANA (quoted above) the presence of anti-phospholipid (PL) Ab, responsible for false positive Wasserman reactions and also known as anti-cardiolipin (CL) Ab, have also been reported in malaria. A potential role for anti-PL AAb in the anti-malaria protective (anti-toxic as well as antiparasite) immunity can be better understood if the following observations are taken into account: (i) parasite phospholipids may induce the expression of inflammatory cytokine such as TNF (Bate et al. 1992a), (ii) anti-PL AAb may modulate the synthesis of TNF in mice (Bate et al. 1992b), (iii) immunisation of mice with phospholipids, such as phosphatidylcholine, induces partial protection against the infection by $P$. chabaudi (Bordmann et al. 1998), and (iv) Gambian children with cerebral malaria presented significantly less IgM antiphosphatidilinositol $\mathrm{Ab}$ than those with non severe malaria (Facer \& Agiostratidou 1994). In another study however, Soni et al. (1993) could not find any correlation between levels of anti-CL Ab, parasitaemia, severity of disease or cerebral manifestations and splenomegaly even though these $\mathrm{Ab}$ were observed at frequencies and titres significantly higher among malarious than among control individuals.

It is obvious that, if it is claimed that an AI response can act on parasites, the existence of cross-reactions between $\mathrm{AAg}$ and parasite $\mathrm{Ag}$ should be detected. A close relationship between these Ag has already been demonstrated even with the aid of parasite specific monoclonal Ab (DanielRibeiro et al. 1984c). Work presently being undertaken in our laboratory showing that sera from AI patients as well as mouse monoclonal AAb react with different $P$. falciparum isolates represent additional evidence to the existence of Ag sharing by host and parasite. Such cross-reactions could also be at the origin of false positive reactions of diagnostic (dipstick) tests which use Ag considered parasite specific, such as the histidine rich protein-2Ag of P. falciparum (Laferi et al. 1997).

Work done at the Pasteur Institute (Ternynck et al. 1991) shows that mice experimentally infected with $P$. chabaudi develop, simultaneously to a marked degree of PBA, intense immunological activity against actin, myoglobin, myosin, spectrin and tubulin AAg as well as against trinitrophenylated (TNP)-ovalbumin. The response, detected at the level of RBC membrane $\mathrm{Ag}$ (such as spectrin and band $3 \mathrm{Ag}$ ) as well as of $\mathrm{Ag}$ studied on fibroblast preparations (such as tubulin, actin and the $70 \mathrm{Kd}$ heat shock protein) persisted for several weeks after parasite clearance before returning to pre-infection values. Follow- ing a challenge with parasitised erythrocytes, and curiously after injection of normal RBC to animals that had already cleared the parasitaemia, a similar increase of $\mathrm{AAb}$ was consistently observed. The polyreactivity of these "natural" AAb must be emphasised: after absorption and elution from infected mouse RBC or affinity-purification on a mouse tubulin immunoadsorbent, they react with all Ag of the panel including parasite extracts.

It must also be stressed that malaria, like certain types of AI diseases such as SLE, is a disease associated with a marked PBA phenomenon and that, for this reason, a given phenomenon may be more easily demonstrated if investigated at the level of responses seemingly secondary to the network of immunological interactions potentiated by the PBA effect. One example could be the cross-reactions between idiotypic, plasmodial and heterologous Ag, already demonstrated (Daniel-Ribeiro et al. 1992).

\section{CAN ANTI-PARASITE ANTIBODIES PRESENT AN AUTOANTIBODY ACTIVITY WITHOUT BEING HARMFUL TO THE ORGANISM?}

A fundamental question that needs to be clarified, concerns the possibility of induction of an efficient protective response (as an anti-parasite heterologous response) but inoffensive to the organism (as an AI response). Indeed, when Jarra (1983) considered that, in order to be effective, the immune response against the parasite would need to include an AI response, he admitted that this could even be at the risk of inducing an immunopathology. Studies published so far, lead us to believe that this is not necessarily the case.

Although this is still a matter of discussion (Dighiero 1997) it may be considered that two types of $\mathrm{AAb}$ (or of cellular AI responses) exist. One type corresponds to the AAb which accompany the AI diseases (let us call them pathogenic $A A b$ ). Examples are anti-DNA $\mathrm{Ab}$ or ANA associated with SLE, anti-erythrocyte AAb of the AI haemolytic anaemias, rheumatoid factors of rheumatoid arthritis (RA), anti-thyroid and anti-thyroglobulin AAb associated with AI thyroiditis; to cite only a few (Bach 1993). The second type comprises the so-called "natural AAb" described by the team of Avrameas at the Pasteur Institute of Paris (Guilbert et al. 1982, Dighiero et al. 1982). These AAb, present in all normal individuals, are characterised by such a degree of polyreactivity that they can be completely absorbed, regardless of their basic reactivity, by sucessive affinity purification on immunoadsorbent with only three $\mathrm{Ag}$ : DNA, TNP and actin (Dighiero, pers. commun.).

Dighiero (1997) considers that although "selfreactive", the natural AAb (as well as the patho- 
genic AAb) are not "self-specific", in as much as they recognise AAg for which no polymorphism has yet been demonstrated and which are present in all individuals of the same species and in several species. The natural AAb could thus play a major role as a first defence barrier of the organism. Finally, some data seem to indicate that pathogenic $\mathrm{AAb}$ result from an $\mathrm{Ag}$ driven somatic mutation process rather than from a polyclonal activation of germ-line clones able to produce natural AAb (reviewed by Dighiero 1995).

The most important argument in favour of the idea that the AAb may not be associated with any immunopathology is based on the work done by Avrameas and Dighiero's group (Dighiero et al. 1982, 1983). These authors were able to study 612 monoclonal proteins from patients with multiple myeloma or Waldenstron macroglobulinaemia and demonstrated that 36 of them presented a natural $\mathrm{AAb}$ activity (actin for 32 of them, DNA, thyroglobulin) without evidence of any clinical manifestation of AI disease.

Thus, the detection of these natural AAb at high frequencies and levels among malaria infected mice (Ternynck et al. 1991) could indicate the attempt of the infected organism to mobilise the relevant immune response for its defence. This could also explain - at any rate, in part - the severity of the experimental infection of the $\mathrm{CBA} / \mathrm{N}$ mice, incapable of developing $\mathrm{AAb}$ against bromelin treated mouse RBC (Jayawardena at al. 1979). These mice are deficient in CD5+ B cells - believed to be the source of virtually all natural AAb (Sidman et al. 1986).

It is also important to draw attention to the fact that the AAb formed in the course of several infectious and parasitic diseases, and those encountered in $\mathrm{AI}$ diseases often recognise the same $\mathrm{AAg}$, but have neither the same fine specificity nor the same biological properties, even though they often share idiotypes in common and even similar structures.

In this respect, reference should be made to the work done by Lloyd et al. (1994) comparing monoclonal AAb obtained from AI mice with those produced by splenocytes of $P$. berghei infected animals. While presenting public idiotype of the same family as those usually encountered in anti-DNA $\mathrm{AAb}$ associated with SLE and other AI diseases, the latter presented specificities different from those of the first group and reacted also with parasite infected erythrocytes.

In the same way it has been observed that antiPL AAb present different profiles of epitopic specificities in syphilis, malaria, and a subset of thrombotic lupic patients, although presenting comparable anti-CL activity (Colaço \& Male 1985). Similarly, Hunt et al. (1992) reported that purified anti-
CL AAb from AI patients reacted with a plasma protein binding to $\beta 2$ glycoprotein I in contrast with those isolated from patients with malaria, infectious mononucleosis, turberculosis, hepatitis A or syphilis that did not require the presence of this ligand to react with $\mathrm{CL}$. The $\mathrm{AAb}$ from the first group, and not those from infected patients, were associated with thrombotic complications.

\section{PROTECTION OFFERED BY MALARIA AGAINST THE DEVELOPMENT OF AUTOIMMUNE DISEASES}

A last set of arguments showing that the AI response in malaria is not necessarily harmfull, is based on epidemiological observations. Taking into account simply the existence of a protection of autoimmunity against malaria and a fortiori if this effect were indissociable from the induction of an AI pathology, an increase in the frequency of AI diseases (including SLE, prototype of AI disease) in malaria hyperendemic areas, should logically be observed. But this is not the case.

More than 30 years ago Greenwood (1968) observed, on the contrary, that the lists of admission to a Nigerian hospital presented few cases of AI diseases. Only 104 out of 98,454 admissions were classified as AI diseases, including 2 SLE and 42 RA, considerably less (respectively 4 and 6 times) than the figures expected for European populations. Greenwood (1968) proposed that parasitic diseases - especially malaria - could prevent the development of AI diseases. In contrast with the relatively low frequency in West Africans, SLE is more common in the American black population - originating particularly from West Africa - than in white American individuals (Lee \& Siegel 1976, Symmons 1995). Following Greenwood's initial epidemiological observation, an original work by Greenwood et al. (1970b) showed that experimental malarial infection was able to prevent the spontaneous development of the SLE like AI disease frequently present in NZBxNZW F1 hybrid mice.

For a long time, this interesting and striking information was neglected until recent progress in the knowledge of immunological mechanisms involved in the malaria pathogenesis and of factors predisposing to SLE, showed that a possible link between these diseases could involve TNF (Jacob \& McDevitt 1988, Butcher \& Clark 1990, Butcher 1991, Adebajo 1992, Jacob 1992). Individuals presenting class-II HLA Ag (DR2, DQW1) which predispose to the development of SLE and of which monocytes are low in vitro producers of TNF, develop lupic nephritis in contrast with those who also have a genetic predisposition (DR3) but produce a high level of TNF. In addition, the low TNF producer individuals predisposed to nephritis are 
protected from this condition by repeated TNF injections. Butcher (1991) postulated that the absence of malaria leads to a decreased TNF production, increasing the risk of SLE development (this would be the reason for the greater frequency in the American black population).

However, TNF is certainly not the sole way whereby malaria would prevent or retard SLE development. Studying also the experimental model of NZBxNZW mice, Hentati et al. (1994) were able to observe a 6-month delay in the occurrence of SLE in. P. chabaudi infected mice. The injection of polyclonal IgG or IgM or of cryoglobuline from infected mice had the same property, although less marked. Compared to normal Ig, the polyclonal Ig had an increased quantity of natural AAb bearing the D23 idiotypes characteristic of natural polyreactive AAb with anti-Fc and anti-Fab activities. The level of anti-DNA AAb, particularly those of the IgG1 isotype, in the mice surviving the development of the AI diseases was diminished. The authors concluded that malarial infection induces the synthesis of IgG and IgM natural AAb endowed with immunoregulating properties able to restore at least temporarily the natural $\mathrm{AAb}$ network which is deficient in $\mathrm{B} / \mathrm{W}$ mice and thus to prevent the development of AI disease. In other words, they could be meaning to suggest that AI diseases are not caused by an excess of "bad" AAb but rather by a lack of the "good" ones.

Malaria associated autoimmunity can also be prevented by the injection of cryoglobulin (obtained from infected mice) prior to P. berghei experimental infection. The animals thus treated developed lower levels of circulating immune-complexes and of AAb against nuclear and cytoplasmatic Ag and did not produce cryoglobulin. This is a long-lasting effect, since the administration of cryoglobulin has an identical effect 10 days or 9 months before infection, suggesting that mice can be actively immunised against the production of AAb (Fawcett et al. 1989).

\section{PROPOSED EXPERIMENTS}

To contribute to further knowledge of the interactions between AI phenomena and anti-parasite immune protection, certain experiments should be envisaged. We hereby propose some which could help to demonstrate a protective effect of autoimmunity against malaria.

- To characterise the existence of cross-reactions between parasite and host antigens by studying the reactivity of monoclonal $\mathrm{AAb}$ (or Ab produced during the acute phase of AI diseases) against parasite $\mathrm{Ag}$ (or corresponding synthetic peptides), and the reactivity of parasite specific $\mathrm{Ab}$ against $\mathrm{AAg}$.
This could be achieved by immunoblotting technique (Towbin \& Gordon 1984) using parasite total extracts (and normal erythrocyte control extracts) or by ELISA with the aid of different synthetic peptides corresponding to parasite $\mathrm{Ag}$, specially those suspected of being involved in immunoprotection. It might be important to include in the study the overall Igs produced in the course of malaria as well as of AI diseases - and not solely those with an AAb or an anti-parasite evidenced activity - since this strategy could allow the evaluation of other $\mathrm{Ab}$ (anti-idiotypic for instance) mobilised in response to the aggressor phenomenon.

- To study the effect of IgG showing AAb activity (and/or obtained from patients with active or inactive SLE or RA) alone or in the presence of human monocytes $(\mathrm{M} \varnothing)$ on the in vitro growth of $P$. falciparum (Trager \& Jensen 1976).

It has been effectively demonstrated that the serum from adult individuals living in malarial endemic areas for sufficiently long periods to acquire clinical immunity (premmunition), can inhibit the in vitro P. falciparum growth (Wilson \& Philips 1976). In addition, Bouharoun-Taoun and Druilhe (1992) have demonstrated that IgG from immune individuals presented various degrees of capacity to inhibit the in vitro proliferation of $P$. falciparum in the presence of normal monocytes and, that this activity, so called $\mathrm{Ab}$ dependent cell inhibition (ADCI), was in the IgG1 and IgG3 fractions of the immune sera.

- To study the evolution of $P$. yoelii experimental malaria in mice spontaneously developing a SLE like AI disease (NZB, F1 NZBxNZW, NRL/1, BxSB).

If the AI response can effectively act against Plasmodia, it can be assumed that sponstaneously AI mice could control the development of parasitaemia more effectively than normal animals (with similar genetic background) or even than young animals of the same strain (before the age of AI disease development).

- To study, in a model of experimental malaria induced (serum transferable) immune-protection ( $P$. yoelii-CBA mice - Jayawardena et al. 1978, $P$. chabaudi-C3H mice - Lima et al. 1991), the effect of prior absorption of serum by AAg, on the transferred protection.

Absorption on tissue AAg or by immunopurification using immunoadsorbants coated with $\mathrm{Ag}$ recognized by natural $\mathrm{AAb}$ (actin, thyroglobulin, DNA) must be provided. A neutralizing effect on protection observed after absortion would imply an autoreactivity of anti-parasite protective $\mathrm{Ab}$ and constitute strong evidence of the existence of the proposed mechanism. 
Traditionally, immunology accepts as a paradigm that the immunisation of individuals, for the purpose of vaccination, must not result in the induction of an AI response. The questioning of this notion and, inversely, the demonstration of a beneficial role of autoimmunity in the process of acquiring protective anti-parasitic immunity could justify the elaboration of new strategies for the immunoprophylatic approach of parasitic disease control in the future. Some of the experiments described above are being undertaken in our laboratory and can bring more light to this approach of the immune protection against malaria.

\section{ACKNOWLEDGEMENTS}

To Graziela Zanini and Marjolein Snippe for help in the editorial work, to Mrs Stella Albaret for reviewing the english text, and to Dr LF Souza Passos for his valuable comments and criticism.

\section{REFERENCES}

Adebajo AO 1992. Does tumor necrosis factor protect against lupus in west Africans? Arthritis and Rheum 35: 839.

Bach JF 1993. La reconnaissance du soi et ses dérèglements: maladies auto-immunes, autoimmunité physiologique et pathplogique. In JF Bach, Traité d'Immunologie, Flammarion Médécine-Sciences, Paris, p. 751-786.

Bate CAW, Taverne J, Bootsma HJ, Mason RCStH, Skalko N, Gregoriadidis G, Playfair JHL 1992a. Antibodies against phosphatidylinositol and inositol monophosphate specifically inhibit tumor necrosis factor induction by malaria exoantigens. Immunology 76: 35 .

Bate CAW, Taverne J, Roman E, Moreno C, Playfair JHL 1992b. TNF induction by malaria exoantigens depends upon phospholipid. Immunology 75: 129.

Ben-Slama L 1982. L'Auto-immunité dans le Paludisme: Étude de la Fréquence des Auto-anticorps Antinoyaux et Anti Muscle Lisse en Fonction du Degré d'Immunité Anti-paludéene, Phd Thesis, Faculté de Médecine Pitié Salpétrière, Université de Paris VI.

Bordmann G, Rudin W, Favre N 1998. Immunization of mice with phosphatidylcholine drasticaly reduces the parasitaemia of subsequent Plasmodium chabaudi blood-stage infections. Immunology 94: 35-40.

Bouharoun-Tayon H, Druilhe P 1992. Plasmodium falciparum malaria: evidence for an isotype imbalance which may be responsible for delayed acquisition of protective immunity. Infect Immun 60: 14731481.

Burger-Rolland L, Ballet JJ, Daniel-Ribeiro CT 1992. Kinetics of antigen specific and non specific polyclonal B-cell responses during lethal $P$. yoelii malaria. Mem Inst Oswaldo Cruz 87: 197-204.

Butcher GA 1991. Does malaria select for predisposition to auto-immune disease? J Roy Soc Med 84: 451-453.

Butcher GA, Clark IA 1990. SLE and malaria: another look at an old idea. Parasitol Today 6: 259-261.
Colaço CB, Male DK 1985. Anti-phospholipid antibodies in syphillis and a thrombotic subset of SLE: distinct profiles of epitope specificity. Clin Exp Immunol 59: 449-456.

Daniel-Ribeiro CT 1988. Polyclonal B-cell activation: What have we learned from the study of malaria? Mem Inst Oswaldo Cruz 83: 633-648.

Daniel-Ribeiro CT, Alfred C, Monjour L, Gentilini M 1984a. Normal frequency of anti-thyroglobulin antibodies in hyperendemic areas of malaria: relevance to the understanding of auto-antibody formation in malaria. Trop Geogr Med 36: 323-328.

Daniel-Ribeiro CT, Ben-Slama L, Gentilini M 1991. Anti-nuclear and anti-smooth muscle antibodies in Caucasians, Africans and Asians with acute malaria. J Clin Lab Immunol 35: 109-112.

Daniel-Ribeiro CT, de Roquefeuil S, Druilhe P, Monjour L, Homberg JC, Gentilini M 1984b. Abnormal anti single-stranded activity in sera from Plasmodium falciparum infected individuals. Trans $R$ Soc Trop Med Hyg 78: 742-746.

Daniel-Ribeiro CT, Deslandes D, Ferreira-Da-Cruz MF 1992. Cross-reactions between idiotypes, Plasmodium falciparum derived peptides, dinitrophenyl and B (2-6) polyfructosan. J Clin Lab Immunol 36: 2326.

Daniel-Ribeiro CT, Druilhe P, Monjour L, Homberg JC, Gentilini M 1983. Specificity of autoantibodies in malaria and the role of polyclonal activation. Trans $R$ Soc Trop Med Hyg 77: 185-188.

Daniel-Ribeiro CT, Kalil J, Monjour L, Alfred C, Ploton I, Gentilini M 1984c. Cross reactions between Plasmodium falciparum and mammalian tissue antigens detected by monoclonal antibodies. Ann Trop Med Parasitol 78: 75-76.

De Souza JB, Playfair JHL 1983. Anti-lymphocyte autoantibody in lethal malaria and its suppression by non lethal malaria. Parasite Immunol 5: 257-265.

Dighiero G 1995. Natural autoantibodies in humans: their relevance in autoimmunity and lymphoproliferative disorders. FORUM Trends Exp Clin Med 5: 58-71.

Dighiero G 1997. Natural autoantibodies, tolerance and autoimmunity. Ann NY Acad Sci 815: 182-192.

Dighiero G, Guilbert B, Avrameas S 1982. Naturally occurring antibodies against nine common antigens in human sera. II. High incidence of monoclonal Ig exibiting activity against actin and tubulin and sharing antibody specificities with natural antibodies. $J$ Immunol 128: 2788-2792.

Dighiero G, Guilbert B, Fermant JP, Lymberi P, Danon F, Avrameas S 1983. Thirty six human monoclonal immunoglobulins with antibody activity against cytoskeleton proteins, thyroglobulin and native DNA: Immunologic studies and clinical correlations. Blood 62: 264-270.

Facer CA 1980. Direct Coombs antiglobulin reactions in Gambian children with Plasmodium falciparum malaria II: Specificity of erythrocyte-bound IgG. Clin Exp Immunol 39: 279-288.

Facer CA, Agiostratidou G 1994. High levels of antiphospholipid antibodies in uncomplicated and severe Plasmodium falciparum and in $P$. vivax malaria. 
Clin Exp Immunol 95: 304-309.

Facer CA, Bray RS, Brown J 1979. Direct Coombs antiglobulin reactions in Gambian children with Plasmodium falciparum malaria: incidence and class specificity. Clin Exp Immunol 35: 119-127.

Fawcett PT, Fawcett LB, Doughty RA, Coleman RM, 1989. Suppression of malaria-induced auto-immunity by immunization with cryoglobulins. Cell Immunol 118: 192-198.

Freeman RR, Parish CR 1978. Polyclonal B-Cell activation during rodent malarial infections. Clin Exp Immunol 32: 41-45.

Greenwood BM 1968. Auto immune disease and parasitic infections in Nigerians. Lancet 1: 380-382.

Greenwood BM, Herrick EM, Holborow EJ 1970a. Speckled antinuclear factor in African sera. Clin Exp Immunol 7: 75-83.

Greenwood B, Herrick EM, Voller A 1970b. Suppression of auto-immune disease in NZB and (NZB x NZW) F1 hybrid mice by infection with malaria. Nature 226: 266-267.

Guilbert B, Dighiero G, Avrameas S 1982. Naturally occurring antibodies against nine common antigens in human sera. I. Detection, isolation and characterization. J Immunol 128: 2779-2787.

Hentati B, Sato MN, Payelle-Brogard B, Avrameas S, Terrynck T 1994. Beneficial effect of polyclonal immunoglobulins from malaria infected $\mathrm{Balb} / \mathrm{c}$ mice on the lupus-like syndrome of (NZB x NZW) F1 mice. Eur J Immunol 24: 8-15.

Hogh B, Petersen E, Crandall I, Gottschau A, Sherman IW 1994. Immune responses to band 3 neoantigens on Plasmodium falciparum-infected erythrocytes in subjects living in an area of intense malaria transmission are associated with low parasite density and high hematocrite value. Infect Immun 62: 4362-4366.

Hunt JE, McNeil HP, Morgan GJ, Crameri RM, Krillis SA 1992. A phospholipid-beta-2-glycoprotein I complex is an antigen for anticardiolipin antibodies occurring in auto-immune disease but not with infection. Lupus 1: 75-81.

Jacob CO 1992. Tumor necrosis factor- $\alpha$ in auto-immunity: pretty girl or old witch? Immunol Today 13: 122-125.

Jacob CO, McDevitt HO 1988. Tumour necrosis factor$\alpha$ in murine auto-immune "lupus" nephritis. Nature 331: 356-358.

Jarra W 1983. Protective immunity to malaria and antierythrocyte autoimmunity. Ciba F Symp 94: 137158.

Jayawardena AN, Targett GAT, Leuchars E, Davies AJS 1978. The immunological response of CBA mice to $P$. yoelii II. The passive transfer of immunity with serum and cells. Immunology 34: 157-165.

Jayawardena AN, Janeway CAJr, Kem JD 1979. Experimental malaria in the CBA/N mouse. J Immunol 123: 2532-2539

Kataaha PK, Facer CA, Mortazavi-Milani SM, Stierle H, Holborow EJ 1984. Stimulation of autoantibody production in normal blood lymphocytes by malaria culture supernatants. Parasite Immunol 6: 481-492

Kreier JP, Dilley DA 1969. Plasmodium berghei: nucleic acid agglutinating antibodies in rats. Exp Parasitol 26: $175-180$.

Laferi H, Kander K, Pichler H 1997. False positive dipstick test for malaria. New Engl J Med 337: 1635.

Lee SL, Siegel M 1976. Systemic lupus erytemathosus: epidemiological clues to pathogenesis. In D Dumonde, Infection and Immunology in the Rheumatic Diseases, Blackwell, p. 307-317.

Lefrançois G, Bouvet E, Le Bras J, Vroklans M, Simonneau M, Vachon F 1981. Anti-erythrocyte autoimmunisation during chronic falciparum malaria. Lancet 2: 661-664.

Lefrançois G, Bouvet E, Le Bras J, Vroklans M, Simonneau M, Vachon F 1982. Anti-erythrocyte autoimmunisation during chronic falciparum malaria. Lancet 1: 280-281.

Lima MR, Bandeira A, Falanga P, Freitas AA, Kipnis TL, Da Silva LP, Coutinho A 1991. Clonal analysis of B-lymphocyte responses to $P$. chabaudi infection of normal and immunoprotected mice. Int Immunol 3: 1207-1216.

Lloyd CM, Collins I, Belcher AJ, Manuelpillai N, Wozencraft AO, Staines NA 1994. Characterization and pathological significance of monoclonal DNAbinding antibodies from mice with experimental malaria infection. Infect Immun 62: 1982-1988.

Playfair JH, De-Souza JB, Hutchings PR, Cooke A 1985. Partial cross-reactivity by suppressor cells induced during different experimental auto-immune diseases. Clin Exp Immunol 59: 117-122.

Poels LG, Van Niekerk CC, Van der Sterren-Reti V, Jerusalem C 1980. Plasmodium berghei: T-cell-dependent auto-immunity. Exp Parasitol 49: 97-105.

Quakyi IA, Voller A, Hall AP, Johbson GD, Holborow DJ, Moody AH 1979. Immunological abnormalities in caucasians with malaria. Immunol Lett 1: 153-154.

Rosenberg Y 1978. Autoimmune and polyclonal B cell responses during murine malaria. Nature 274: 170172.

Sayles PC, Wassom DL 1992. Are antibodies important in mice infected with Plasmodium yoelii? Parasitol Today 8: 368-370

Sidman CL, Shultz LD, Hardy RR, Hayakawa K, Herzenberg LA 1986. Production of immunoglobulin isotypes by Ly-1+ B cells in viable motheaten and normal mice. Science 232:1423-12425.

Soni PN, De-Bruyn CC, Duursma J, Sharp BL, Pudifin DJ 1993. Are anticardiolipin antibodies responsible for some of the complications of severe acute Plasmodium falciparum malaria? S Afr Med J 83: 660662.

Sorensen PG, Mickley H, Schmidt KG 1984. Malariainduced immune thrombocytopenia. Vox Sang 47: 68-72.

Symmons DP 1995. Frequency of lupus in people of African origin. Lupus 4: 176-178.

Ternynck T, Falanga PB, Unterkirscher C, Gregoire J, Da-Silva LP, Avrameas S 1991. Induction of high levels of IgG autoantibodies in mice infected with P. chabaudi. Int Immunol 3: 29-37.

Towbin H, Gordon J 1984. Immunoblotting and dot Immunobinding - current status and outlook. $J$ 
Immunol Meth 72: 312-314.

Trager W, Jensen JB 1976. Human malaria parasites in continuous culture. Science 193: 673-675.

Voller A, O’Neill P, Humphrey D 1972. Serological Indices in Tanzania - II. Antinuclear factor and malaria indices in populations living at different altitudes. J Trop Med Hyg 75: 136-139.

Wilson RJM, Philips RS 1976. Method to test inhibitory antibodies in human sera to wild populations of Plasmodium falciparum. Nature 263: 132-134.

Wozencraft AO, Lloyd CM, Staines NA, Griffths VJ
1990. Role of DNA-binding antibodies in kidney pathology associated with murine malaria infections. Infec Immun 58: 2156-2164.

Zouali M, Druilhe P, Eyquem A 1986. IgG-subclass expression of anti-DNA and anti-ribonucleoprotein autoantibodies in human malaria. Clin Exp Immunol 66: 273-278.

Zouali M, Druilhe P, Gentilini M, Eyquem A 1982. High titres of anti-T antibodies and of other haemagglutinins in human malaria. Clin Exp Immunol 50: 83-91. 